\title{
Comparisons of neuroinflammation, microglial activation, and degeneration of the locus coeruleus-norepinephrine system in APP/PS1 and aging mice
}

Song Cao ${ }^{1,2,3}$, Daniel W. Fisher ${ }^{3,4}$, Guadalupe Rodriguez ${ }^{3}$, Tian Yu² and Hongxin Dong ${ }^{3^{*}}$

\begin{abstract}
Background: The role of microglia in Alzheimer's disease (AD) pathogenesis is becoming increasingly important, as activation of these cell types likely contributes to both pathological and protective processes associated with all phases of the disease. During early AD pathogenesis, one of the first areas of degeneration is the locus coeruleus (LC), which provides broad innervation of the central nervous system and facilitates norepinephrine (NE) transmission. Though the LC-NE is likely to influence microglial dynamics, it is unclear how these systems change with AD compared to otherwise healthy aging.
\end{abstract}

Methods: In this study, we evaluated the dynamic changes of neuroinflammation and neurodegeneration in the LCNE system in the brain and spinal cord of APP/PS1 mice and aged WT mice using immunofluorescence and ELISA.

Results: Our results demonstrated increased expression of inflammatory cytokines and microglial activation observed in the cortex, hippocampus, and spinal cord of APP/PS1 compared to WT mice. LC-NE neuron and fiber loss as well as reduced norepinephrine transporter (NET) expression was more evident in APP/PS1 mice, although NE levels were similar between 12-month-old APP/PS1 and WT mice. Notably, the degree of microglial activation, LC-NE nerve fiber loss, and NET reduction in the brain and spinal cord were more severe in 12-month-old APP/PS1 compared to 12- and 24-month-old WT mice.

Conclusion: These results suggest that elevated neuroinflammation and microglial activation in the brain and spinal cord of APP/PS1 mice correlate with significant degeneration of the LC-NE system.

Keywords: Alzheimer's disease, Locus coeruleus, Norepinephrine/noradrenaline, Microglia, Norepinephrine transporter, Noradrenergic, Dopaminergic, Spinal cord

\footnotetext{
* Correspondence: h-dong@northwestern.edu

${ }^{3}$ Department of Psychiatry and Behavioral Sciences, Northwestern University

Feinberg School of Medicine, 303 East Chicago Avenue, Chicago, IL 60611,

USA

Full list of author information is available at the end of the article
}

(C) The Author(s). 2021 Open Access This article is licensed under a Creative Commons Attribution 4.0 International License, which permits use, sharing, adaptation, distribution and reproduction in any medium or format, as long as you give appropriate credit to the original author(s) and the source, provide a link to the Creative Commons licence, and indicate if changes were made. The images or other third party material in this article are included in the article's Creative Commons licence, unless indicated otherwise in a credit line to the material. If material is not included in the article's Creative Commons licence and your intended use is not permitted by statutory regulation or exceeds the permitted use, you will need to obtain permission directly from the copyright holder. To view a copy of this licence, visit http://creativecommons.org/licenses/by/4.0/ The Creative Commons Public Domain Dedication waiver (http://creativecommons.org/publicdomain/zero/1.0/) applies to the data made available in this article, unless otherwise stated in a credit line to the data. 


\section{Introduction}

Though Alzheimer's disease (AD) is primarily characterized by progressive memory decline, numerous other symptoms appear during the course of the disease, including neuropsychiatric symptoms [1], chronic pain [2], and seizures [3]. Chronic pain in particular also increases with aging, but $\mathrm{AD}$ seems to exacerbate chronic pain both quantitatively and qualitatively $[4,5]$. The cellular and biochemical mechanisms that may contribute to the severity of chronic pain in AD are not well understood. One pathological change noted in the AD brain is microglial activation in the form of disease-associated microglia (DAM), leading to aberrant expression of proinflammatory cytokines in a well-characterized pattern [6-8]. Activated microglia have a nuanced role in AD and highly depend on the disease stage as well as particular activation pattern. DAM cross-seed A $\beta$ oligomers and plaques $[9,10]$ enhance tau spreading and taudriven neurodegeneration and astrogliosis [11-13] and facilitate synapse loss [14]. While these DAM are located around the neuropathological hallmarks of AD and are well correlated with cognitive decline $[15,16]$, it is still unclear how DAM influence other AD symptoms. Further, DAM are not only found in neural regions classically associated with $\mathrm{AD}$ but also in the spinal cord, where it is unclear how they may exacerbate noncognitive AD symptoms, such as chronic pain [17].

Though neurodegeneration in cortical and hippocampal areas has been well studied in $\mathrm{AD}$, the sub-cortical locus coeruleus (LC) is actually one of the first brain regions to undergo degeneration in $\mathrm{AD}$ pathogenesis [18, 19]. As the main source of norepinephrine (NE) in the CNS, the LC plays critical roles in a variety of brain functions, including cognition, attention, emotion, the sleep-wake cycle, and regulation of chronic pain [2022 ]. While some degeneration of LC neurons also occurs in normal aging [23, 24], an estimated 50 [25] to $60 \%$ [26] loss of LC-NE neurons is observed in AD patients, far out-pacing LC loss seen with healthy aging.

Interestingly, microglia are well equipped to respond to NE signaling by expressing $\alpha_{1 \mathrm{~A}}, \alpha_{2 \mathrm{~A}}, \beta_{1}$, and $\beta_{2}$ receptors $[27,28]$. Functionally, microglia are regulated by NE [23, 24, 28, 29], as NE inhibits microglial activation and reduces pro-inflammatory factors such as IL- 6 and TNF$\alpha$ [27]. The mechanism of these anti-inflammatory effects seem to be through activation of $\beta_{1}$ and $\beta_{2}$ receptors, as pharmacological agonism of these receptors in hippocampal slice cultures reduced lipopolysaccharide (LPS)-induced microglial activation and TNF- $\alpha$, IL-6, and MCP-1 production [30]. Similarly, $\beta$-adrenergic agonism in microglia reduced TNF- $\alpha$, IL-6, and free radical expression induced by LPS or prostaglandin E2 and protected co-cultured cortical neurons from death [31, 32]. NE suppressed A $\beta$-induced cytokine and chemokine production, while induced degeneration of noradrenergic neurons increased expression of inflammatory mediators in APP-transgenic mice [23].

Though LC neuron degeneration in AD may exacerbate microglial activation, it is still unclear how this influences NE levels in the brain and spinal cord, as previous studies demonstrate conflicting results in $\mathrm{AD}$ patients $[25,33,34]$. In addition, most of the measures used to detect changes in NE levels depend on bulk estimates from the extracellular milieu, and it is unclear if NE levels and the resultant functional impact are regulated by second messenger signaling downstream of adrenergic $G$ protein-coupled receptors. It is possible that dysfunction in LC-NE neurotransmission leads to downstream deficits in proper adrenergic signaling that are not captured by lower-resolution estimates of total extracellular NE measurements in bulk tissue [35].

Given that the clinical data of NE levels in the AD brain are inconsistent and that there is no animal work comparing the dynamic changes in the LC-NE systems with neuroinflammation in $\mathrm{AD}$ mice, we investigated how microglia and the LC-NE system change during aging and AD-related neuropathogenesis in APP/PS1 mice, a commonly used animal model of AD. Importantly, we made our comparisons across important cortical, subcortical, and spinal cord regions that may influence non-cognitive symptoms that arise during dementia, notably chronic pain.

\section{Materials and methods}

\section{Animals}

A total of 35 APP/PS1 mice (3- and 12-month-old) and 50 WT mice (3-, 12-, and 24-month-old, sex-matched) on a C57BL6/J background were used for this study ( $n=$ 6/group for immunofluorescence studies, $n=4$ /group for cytokine array, $n=6$ /group for NE level studies). The breeders of APP/PS1 mice were purchased form Jackson Laboratory (Bar Harbor, Maine, USA). Animals were given food and water ad libitum and housed on a 12-h light/dark cycle. All experiments were performed under protocols approved by the Northwestern University Animal Care and Use Committee, according to the current Guide for the Care and Use of Laboratory Animals (2011, eighth edition) and NIH guidelines for the treatment of animal subjects.

\section{Immunofluorescence}

Euthasol $^{\circledR}$ (39 mg pentobarbital sodium, $5 \mathrm{mg}$ phenytoin sodium, Virbac, USA) was subcutaneously injected to anesthetize mice. When mice were in deep anesthesia, the heart was exposed, and a 25G needle was inserted into the left ventricle. Mice were perfused with phosphate-buffered saline (PBS) followed by $4 \%$ paraformaldehyde. Then, the intact brain and lumbar spinal 
cord were collected and fixed in $4 \%$ paraformaldehyde overnight at $4{ }^{\circ} \mathrm{C}$, followed by dehydration in $30 \%$ sucrose solution until the tissue sank to the bottom of the bottles. After fixation and dehydration, the whole brain and spinal cord were dissected and embedded in OCT compound, and $35-\mu \mathrm{m}$ slices were cut with a cryostat (CM1850 UV, Leica, Germany). The sections containing the brain areas, i.e., the prelimbic cortex (bregma 1.94 $\mathrm{mm}$ ) of prefrontal cortex (PFC), anterior cingulate cortex (ACC, bregma $0.74 \mathrm{~mm}$ ), the hippocampus (bregma - $2.06 \mathrm{~mm}$ ) encompassing the dentate gyrus (DG) and CA3, and the L4-L6 spinal cord, were collected according to the spatial coordinates of the coronal plane in the mouse brain atlas [36] and mouse spinal cord atlas [37], respectively.

For immunofluorescence staining, brain slices were (1) washed in PBS containing 0.3\% Triton and blocked for $2 \mathrm{~h}$ at room temperature with $1 \%$ bovine serum albumin and $2 \%$ donkey or goat serum; (2) incubated overnight at $4{ }^{\circ} \mathrm{C}$ with primary antibodies: rabbit anti-Iba-1 (1:500, 01919741, Fujifilm Wako, Japan), rabbit anti-tyrosine hydroxylase (TH, 1:500, ab112, Abcam, UK), mouse antinorepinephrine transporter (NET, 1:500, ab211463, Abcam), and mouse anti-A $\beta 42$ (1:500, 05-831-I, Millipore, USA); (3) washed with PBS containing $0.3 \%$ Triton and incubated for $2 \mathrm{~h}$ at room temperature with anti-rabbit Alexa Fluor ${ }^{\circ} 488$ (111-545-003, Jackson ImmunoResearch, USA; or ab150073, Abcam) or anti-mouse Cy3 (ab97035, Abcam) secondary antibodies; and (4) washed in PBS containing $0.3 \%$ Triton before being mounted with mounting medium containing Fluoroshield (ab104139, Abcam). Immunofluorescence pictures were taken with a fluorescence microscope (80i, Nikon, Japan) and CoolSNAP DYNO CCD (Photometrics, Canada).

To quantify Iba- $1, \mathrm{TH}, \mathrm{NET}$, and A $\beta 42$ expression, the brain and spinal cord images (magnification $=\times 100$ ) were outlined with the size-standardized regions of interest (ROIs) by the Image J software (v.1.52a, NIH, USA), and the percentage of area with fluorescence was quantified using this program. In particular, the threshold was set and standardized across images to maximize true protein expression signal for quantification; then, the total pixel number of target protein were recorded, and the percentage was calculated by dividing the pixel number with the total unfiltered pixel number in the ROI. $\mathrm{TH}^{+}$neurons in the LC [38] (bregma $-5.4 \mathrm{~mm}$ [36]) were captured under the same magnification and counted manually [39]. Three sections for each brain and spinal cord region per immunostaining marker were averaged and analyzed. To evaluate non-specific staining, incubation of sections in primary or secondary antibody were conducted for each round of staining, and the resulting images confirmed that the primary and the secondary antibodies did not cause nonspecific staining.

\section{Cytokine array}

Twelve-month-old WT and APP/PS1 mice were anesthetized and perfused with PBS; then, the intact brain and the lumbar and sacral spinal cord segments were collected and stored at $-80^{\circ} \mathrm{C}$. A mouse cytokine array (ARY006; R\&D, Minneapolis, MN, USA) was used to detect cytokine expression patterns in the brain and spinal cord, and the protocol for implementation followed manufacturer's instructions [40]. Briefly, the left half of the brain cut along the midline and the posterior border of the bilateral cerebral cortices as well as the lumbar and sacral spinal cord segments were homogenized in $0.1 \mathrm{M}$ PBS with protease inhibitor cocktail $(20 \mu \mathrm{L} / 100$ mg tissue, P8340, Sigma, Israel). Total protein content was determined with BCA assay kit (23225, Thermo Fisher, USA). Membranes containing antibody arrays were incubated for $2 \mathrm{~h}$ at room temperature with blocking buffer (a buffered protein with preservatives). Five hundred micrograms of protein extracts was diluted in blocking buffer and incubated with the membranes overnight at $4{ }^{\circ} \mathrm{C}$ on a shaker. Then, the membranes were washed with buffered surfactant and incubated for $3 \mathrm{~h}$ at room temperature with the biotinylated antibody cocktail solution. After washing, the membranes were incubated with horseradish peroxidase (HRP)-conjugated streptavidin for $2 \mathrm{~h}$ at room temperature and developed using the detection reagent provided by the manufacturer. Images were captured with 5 min exposure time using the ChemiDoc ${ }^{\mathrm{TM}}$ system (Bio-Rad, USA). Pixel densities were further analyzed using the ImageJ software and normalized to positive controls; then, mean values were calculated.

\section{NE evaluation with high-sensitivity ELISA}

The brain and the lumbar and sacral spinal cord were prepared as described in the cytokine array experiment. NE levels were measured with a high-sensitivity enzymelinked immunosorbent assay (ELISA) kit (NOU39-K01, Eagle Biosciences, USA). The assays apply the competitive enzyme immunoassay technique using a monoclonal antibody specific for each monoamine and a monoamine-HRP conjugate. Standards and samples were incubated together with the corresponding monoamine-HRP conjugate in pre-coated 96-well plates for $1 \mathrm{~h}$. After washing, wells were incubated with a substrate for the HRP enzyme. Finally, a stop solution was added to terminate the reaction, and the intensity of the color was measured at $450 \mathrm{~nm}$ using a microplate reader (FLUOstar Omega, BMG Labtech, Germany). An aliquot of tissue suspended in extraction buffer was used to quantify protein concentration, which was used to normalize NE measurements. NE content was expressed as nanogram/milligram protein. 


\section{Statistical analysis}

All statistical analyses were conducted using GraphPad Prism v.7.0 (GraphPad Software, San Diego, CA, USA). Data are expressed as mean \pm standard deviation. Comparisons between APP/PS1 mice and WT mice across time were estimated with two-way ANOVA, and followed by Tukey's post hoc multiple comparison tests. A repeated-measures ANOVA was not employed as different mice were used at each time point. Cytokine expressions were compared with multiple $t$ tests with false discovery rate (FDR) correction. NE levels were compared with Student's $t$ tests. $P<0.05$ was considered as statistically significant.

\section{Results}

Microglial activation increased with aging in WT and APP/ PS1 mice

Activated microglia have been shown to play a critical role in $\mathrm{AD}$ pathogenesis, and Iba-1 expression in microglia is often used as a marker for activated microglia. To determine the dynamic changes of microglial activation across the lifespan of WT and AD mice, we compared immunofluorescent staining for Iba-1 in cortical and hippocampal regions as well as the spinal cord of WT mice at 3-, 12-, and 24-month-old WT and APP/PS1 mice at 3 and 12 months of age. Reduced survival of 24month-old APP/PS1 mice precluded analyzing this genotype at this time point. Our data showed that in WT mice, the Iba- $1^{+}$area of the prelimbic prefrontal cortex (PFC), ACC, and hippocampal DG and CA3 regions increased significantly with aging (all $P<0.0001$, Fig. 1 ). There were no differences in the expression of Iba- 1 in all regions measured between 3-month-old APP/PS1 and WT mice, a time point before $\mathrm{A} \beta$ plaques were evident (all $P>0.05$, Fig. 1a left column, Fig. 1b-e). However, there was significantly more Iba-1 expression in 12-month-old APP/PS1 in all of these regions compared to age-matched WT counterparts (all $P<0.0001$, Fig. 1a middle column, Fig. 1b-e). Importantly, the expression of Iba-1 was more pronounced in 12-month-old APP/ PS1 mice compared to 24-month-old WT mice in PFC $(5.42 \pm 0.23$ vs $12.62 \pm 0.79, P<0.0001$, Fig. $1 b)$, ACC $(P<0.0001$, Fig. 1c), DG $(P<0.0001$, Fig. $1 \mathrm{~d})$, and CA3 $(P=0.044$, Fig. 1e), suggesting $\mathrm{AD}$ pathogenesis has a greater effect on microglial activation than otherwise healthy aging.

In the lumbar spinal cord, Iba-1 expression followed similar patterns to the brain, as there was increased Iba1 expression with aging in both WT and APP/PS1 mice. Greater Iba-1 expression in AD spinal cords were detected compared to that of age-matched WT mice, and there was a greater degree of Iba-1 expression in 12month-old APP/PS1 mice compared to 24-month-old WT mice (24.15 vs $17.47, n=6, P<0.0001$, Fig. 2 ).
Overall, this confirms greater microglial activation across the CNS in APP/PS1 mice.

Our results suggest $\mathrm{AD}$ pathogenesis is a stronger driver of pathological microglial activation than aging, and so we investigated the colocalization of $A \beta 42$ expression, a pathological hallmark of $\mathrm{AD}$, and $\mathrm{Iba}-1^{+}$ microglia. Throughout cortical (PFC, ACC) and hippocampal regions (DG, CA3), as well as the lumbar spinal cord of 12-month-old APP/PS1 mice, increased Iba-1 and $A \beta 42$ colocalization suggested greater recruitment of Iba- 1 around $A \beta 42^{+}$plaques (Fig. 3). Thus, we confirmed greater pathological microglial activation near $\mathrm{A} \beta 42$ plaques in the APP/PS1 CNS.

\section{Cytokine expression changed with AD status and CNS region}

Activated microglia in $\mathrm{AD}$ could shift from protective cytokines to proinflammatory cytokines, as seen in DAM [41]. We evaluated cytokine expression in the whole brain and the lumbar and sacral spinal cord of 12month-old WT and APP/PS1 mice using a cytokine protein array. Our results indicated that from the 40 detected cytokines, 5 cytokines (C5a, CXCL9, CD54, IL-16, and IL- $1 \alpha)$ were upregulated $(t=3.1,4.3,5.6,7.2,7.3$, and $P=0.021,0.004,0.001,0.0003,0.0003$, respectively) in the brain and 5 cytokines (TIMP-1, TNF- $\alpha$, IL-23, CXCL12, and IL-27) were upregulated $(t=6.8,4.2,6.0$, 2.6, 5.1, and $P=0.0004,0.006,0.0009,0.039,0.002$, respectively) in the spinal cord of APP/PS1 mice compared to age-matched WT mice (Fig. 4). These data suggest that though increased microglia lead to upregulation of particular cytokines, there may be differences in cytokine expression between the brain and spinal cord, which could lead to divergent effects on neuronal and glial homeostasis.

\section{LC-NE neuronal degeneration in APP/PS1 mice}

The main source of NE in the CNS is derived from the neurons in LC, which project widely to cortical, subcortical, and spinal cord regions. As the $\mathrm{LC}$ is one of the first areas affected by AD, we determined the degree of LC neuron loss in WT and APP/PS1 mice at different ages using immunohistochemical analysis (Fig. 5) labeling TH. At high magnification, the TH-positive neurons are packed together, but rarely overlap. $\mathrm{TH}^{+}$neuron counting indicated that LC-NE neurons in WT mice were reduced with aging $(F=76.36, P<0.0001)$, although the numbers of LC-NE neurons in 24-month-old WT mice were not significantly less than that of 3month-old $(P=0.06)$ and 12 -month-old WT mice $(P=$ 0.29 , Fig. $5 \mathrm{~b}$ ). Additionally, the number of $\mathrm{TH}^{+}$neurons in 12-month-old APP/PS1 mice was decreased compared with that of 12-month-old WT mice $(123.4 \pm 4.77$ vs $88.18 \pm 5.74, P=0.0062$, Fig. $5 b$ ), while $\mathrm{LC}-\mathrm{NE}$ 


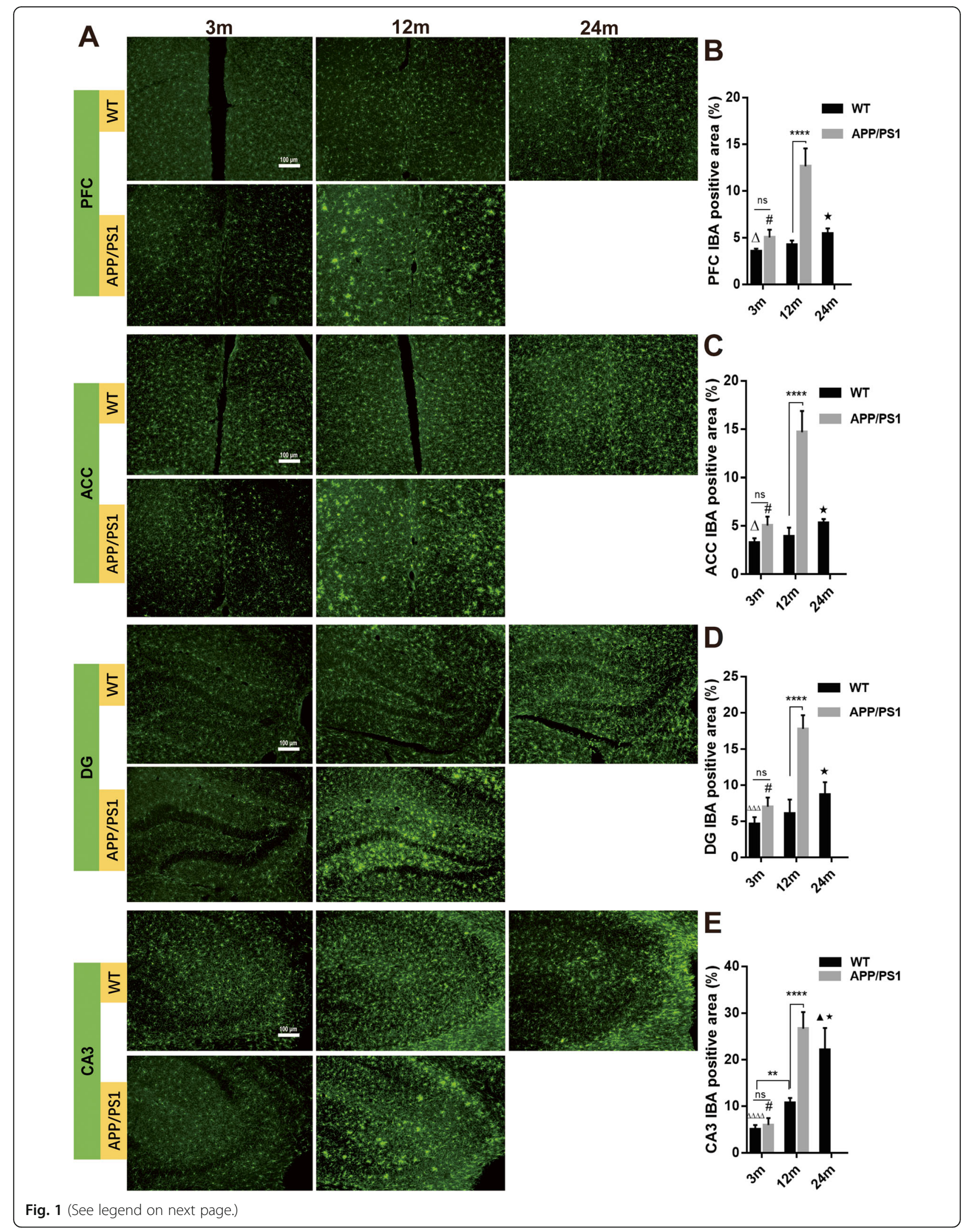


(See figure on previous page.)

Fig. 1 Microglia immunofluorescence of different brain areas in APP/PS1 and WT mice. a Immunofluorescence demonstrated that the Iba- $1^{+}$area in the $\mathbf{b}$ medial prefrontal cortex (PFC), $\mathbf{c}$ anterior cingulate cortex, and $\mathbf{d}$ hippocampal DG, and $\mathbf{e}$ CA3 increased significantly with aging in WT and APP/PS1 mice. In 12-month-old APP/PS1 mice, Iba-1 expression was significantly more than that of 12-month-old WT mice and 3-month-old APP/PS1 mice. In addition, in PFC, ACC, and DG, the Iba- $1^{+}$area in 12-month-old APP/PS1 mice was significantly more than in 24-month old WT mice. $n=6$. ns, not significant. ${ }^{* *} P<0.01 .{ }^{* * *} P<0.0001$. $\# P<0.0001$ compared with 12-month-old APP/PS1 mice. $\boldsymbol{\Delta} P<0.05$ compared with 12-month-old WT mice. $\star P<0.0001$ compared with 12-month-old APP/PS1 mice. $\Delta P<0.05$ compared with 24-month-old WT mice. $\Delta \Delta \Delta P<$ 0.001 compared with 24-month-old WT mice. $\Delta \Delta \Delta \Delta P<0.0001$ compared with 24-month-old WT mice

neuron numbers were similar between $\mathrm{AD}$ and WT mice at 3 months of age $(130.8 \pm 9.273$ vs $127.5 \pm 8.44, P=0.99$, Fig. 5b). Furthermore, there was more $\mathrm{TH}^{+}$neuron loss in 12-month-old APP/PS1 mice as compared to 24-monthold WT mice $(104 \pm 5.75$ vs $88.18 \pm 5.74, P=0.51)$.

\section{NE levels in the brain and spinal cord}

As NE in the brain is mostly generated from LC neurons, and NE is likely to modulate microglial responses to neuroinflammation, we measured the NE levels in bulk tissues from the brain and spinal cord of 12month-old AD and WT mice using ELISA. We focused on the 12-month timepoint, as LC-NE neuron number was not yet different at 3 months between the two groups. We observed no differences in NE levels in either the brain $(t=0.71, P=0.50)$ or spinal cord $(t=$ $0.93, P=0.37$ ) between WT and APP/PS1 mice (Fig. $5 \mathrm{c}$ ), suggesting compensatory mechanisms are able to stabilize NE levels despite significant LC-NE neuron degeneration.
Reduced $\mathrm{TH}^{+}$nerve fibers in the brains and spinal cord of APP/PS1 mice

It is clear that LC-NE neurons degenerated during aging and $\mathrm{AD}$ progression, but it has been noted that increased neurite sprouting has been detected in $A D$, though potentially dystrophic in nature [42]. As we detected similar levels of NE in the CNS of WT and APP/ PS1 mice, we wanted to determine if increased branching of LC-NE afferents could explain these stable NE levels. $\mathrm{TH}^{+}$nerve fibers reflect the axons of noradrenergic or dopaminergic neurons, and so we initially stained for these axons in cortical, hippocampal, and spinal cord regions. Immunofluorescence detection demonstrated decreased $\mathrm{TH}^{+}$nerve fibers in PFC, ACC, DG, and CA3 with aging in both WT and APP/PS1 mice (Fig. 6). Similar to LC-NE degeneration, except for the ACC of 3month-old mice $(10.3 \% \pm 2.3 \%$ vs $8.62 \% \pm 1.9 \%, P=$ 0.35), 3- and 12-month-old APP/PS1 mice demonstrated reduced $\mathrm{TH}^{+}$staining in the brain compared with WT mice of the same age in almost all brain regions studied (all $P<0.05$, Fig. 6b-e). In DG (Fig. 6b), there was less

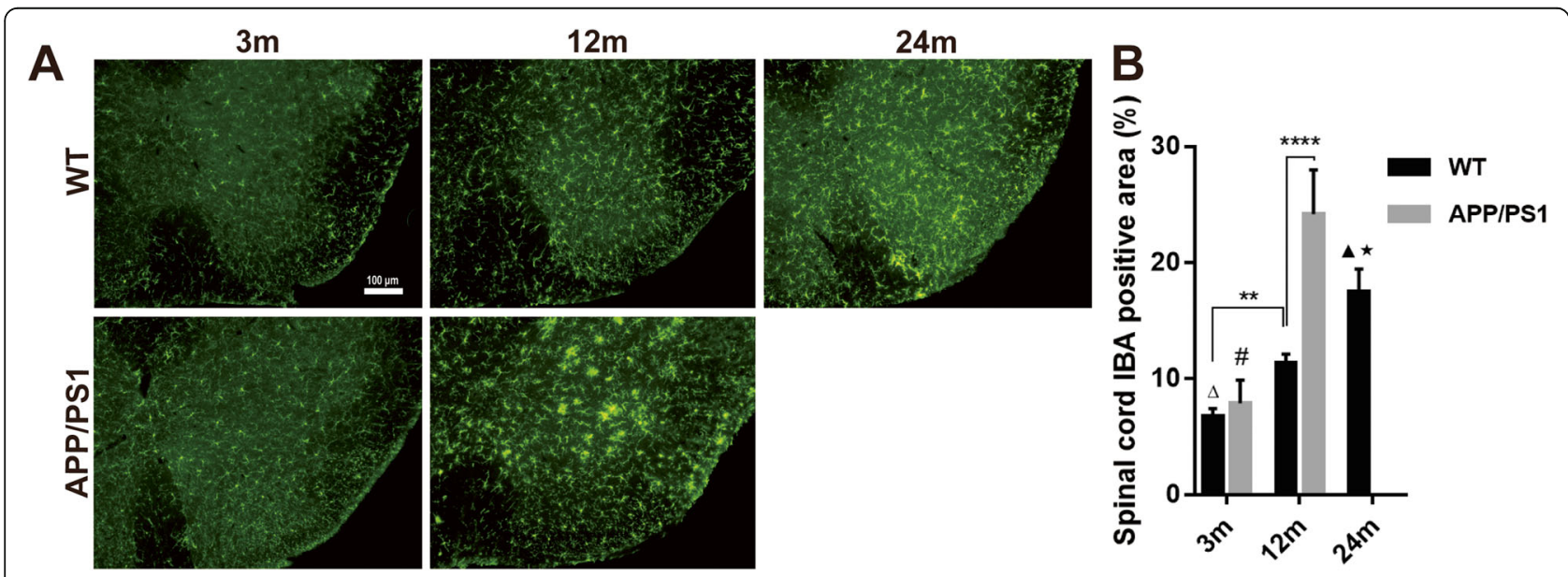

Fig. 2 Microglia immunofluorescence in the spinal cord of APP/PS1 and WT mice. a lba-1 expression in the lumbar spinal cord was detected by immunofluorescence. $\mathbf{b}$ lba-1 expression in the two groups of mice increased significantly with aging. Iba- $1^{+}$area in $12-$ month-old APP/PS1 mice was significantly more than that of 12-month-old WT mice and 3-month-old APP/PS1 mice; it was even more than that in 24-month-old WT mice. $n=6$. ns, not significant. ${ }^{* *} P<0.01$, ${ }^{* * *} P<0.0001$, $\# P<0.0001$ compared with 12-month-old APP/PS1 mice. $\triangle P<0.0001$ compared with 24-month-old WT mice. $\boldsymbol{\Delta} P<0.001$ compared with $12 \mathrm{~m}$ WT mice. $\star P<0.0001$ compared with $12 \mathrm{~m}$ APP/PS1 mice. 


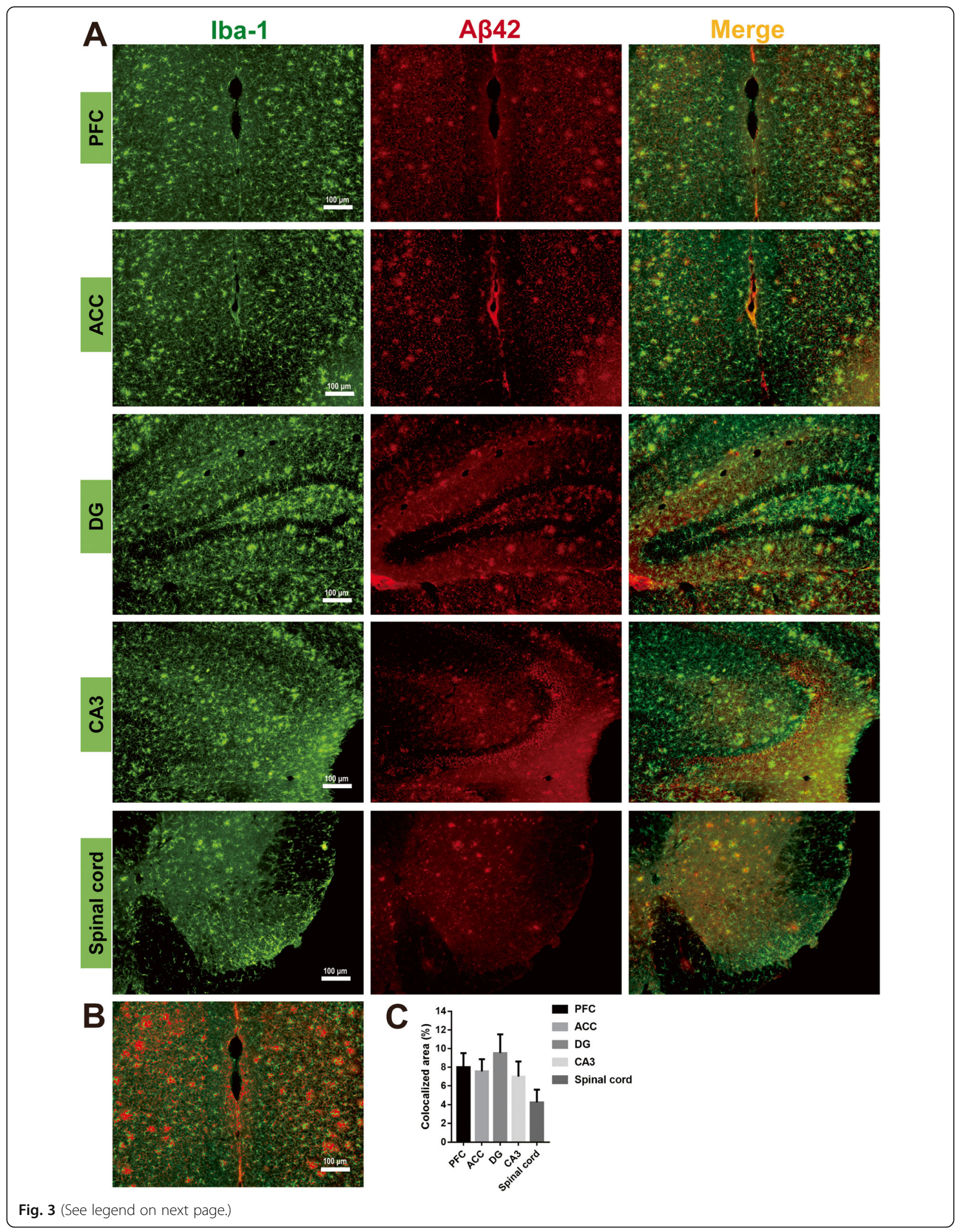


(See figure on previous page.)

Fig. 3 Microglia accumulating around $A B 42^{+}$plaques in the brain and spinal cord. a Iba-1 and $A B 42$ co-staining in $P F C, A C C, D G, C A 3$, and lumbar spinal cord from 12-month-old APP/PS1 mice showed that a large number of microglia activated and accumulated around the AB42 ${ }^{+}$ plaques in the brain and in the grey matter of the spinal cord. $\mathbf{b}, \mathbf{c}$ Iba-1 and A 42 colocalized areas (yellow color in $\mathbf{a}$ ) in PFC were selected and quantified with Image J

$\mathrm{TH}^{+}$area in 12-month-old APP/PS1 mice compared to 24-month-old WT mice $(0.28 \% \pm 0.08 \%$ vs $1.3 \% \pm$ $0.41 \%, P=0.0002$, Fig. $6 \mathrm{~d}$ ), again suggesting that catecholaminergic fiber degeneration is more greatly affected by $\mathrm{AD}$ pathogenesis than by aging.

Results in the lumbar spinal cord were similar to those in the brain: $\mathrm{TH}^{+}$nerve fibers decreased with aging and AD pathogenesis (Fig. 7). Also similar to many parts of the brain, there was a greater reduction of $\mathrm{TH}^{+}$nerve fibers in 3-month-old APP/PS1 mice compared to 3month-old WT mice $(7.43 \pm 0.47$ vs $5.02 \pm 0.34, P=$ 0.0003 , Fig. 7b) and in 12-month-old APP/PS1 mice compared to 12 -month-old WT mice $(5.9 \pm 0.34$ vs 2.5 $\pm 0.15, P<0.0001$, Fig. $7 \mathrm{~b}$ ), again suggesting a more deleterious effect of $\mathrm{AD}$ pathogenesis than aging on catecholaminergic degeneration.

\section{Reduced $\mathrm{NET}^{+}$nerve fibers and NET expression in brains} and spinal cord of APP/PS1 mice

Though $\mathrm{TH}^{+}$neurons could be dopaminergic or noradrenergic, NET reflects only noradrenergic terminals. We stained for NET in APP/PS1 and WT mice to better characterize degeneration of LC-NE nerve terminals in cortical, hippocampal, and spinal cord region with aging. Our data suggest that in PFC, ACC, DG, and CA3, $\mathrm{NET}^{+}$nerve fibers gradually decreased with aging (Fig. 8). $\mathrm{NET}^{+}$nerve fibers in 12-month-old APP/PS1 mice were also significantly reduced compared with WT mice of the same age in PFC, ACC, DG, and CA3 $(P<0.0001$, $P<0.0001, P<0.001$, and $P<0.0001$, respectively, Fig. $8 \mathrm{~b}-\mathrm{e})$, and a greater decrease in $\mathrm{NET}^{+}$fibers was also detected in the PFC $(P<0.0001)$ and DG $(P<0.01)$ of 3 -month old APP/PS1 mice. Similar to the trend of $\mathrm{TH}^{+}$

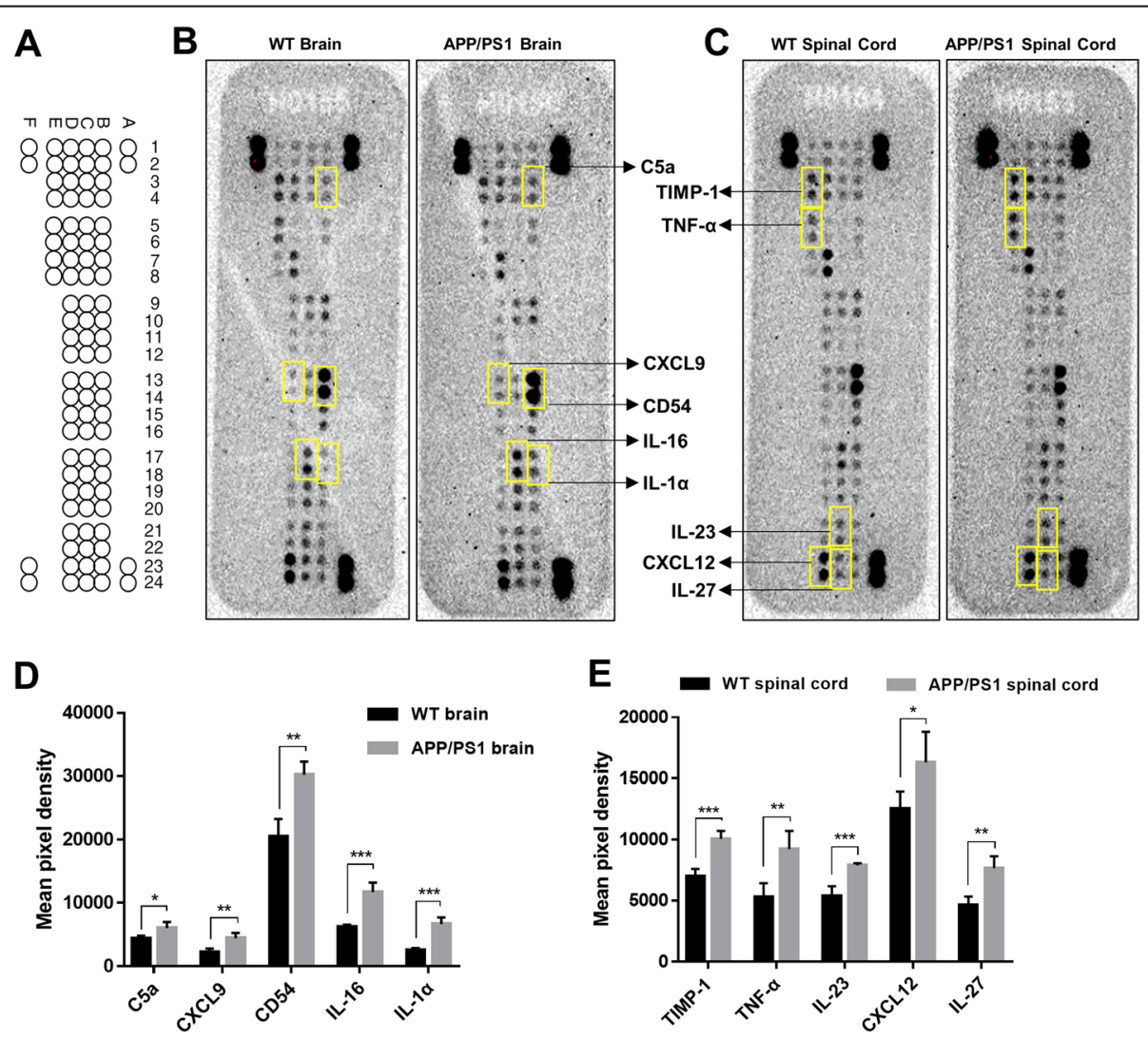

Fig. 4 Comparisons of cytokine expression in the brain and spinal cord of WT and APP/PS1 mice. a Cytokine array coordinates on membranes. $\mathbf{b}$, c Representative membrane images of cytokine expression in the $\mathbf{b}$ brain and $\mathbf{c}$ spinal cord. Compared with WT mice, d 5 cytokines were significantly upregulated in the brain of APP/PS1 mice, and e 5 cytokines were significantly upregulated in the spinal cord of APP/PS1 mice. $n=4$ in each group. Statistical analyses were conducted with multiple $t$ tests with false discovery rate (FDR) correction. ${ }^{*} P<0.05,{ }^{* *} P<0.01$. ${ }^{* * *} P$ $<0.001$ 


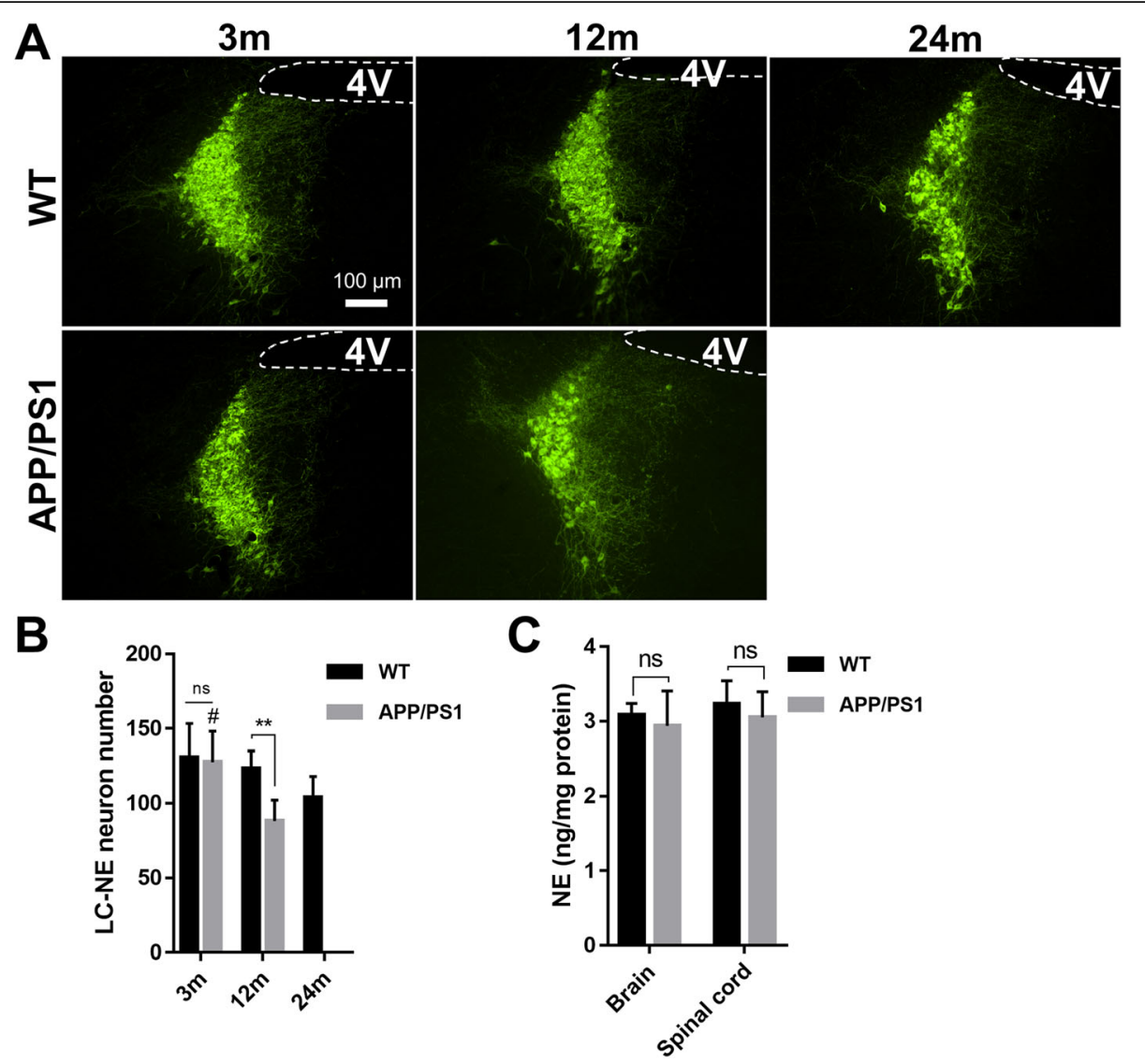

Fig. 5 Immunofluorescence of LC-NE neuron and NE detection in the brain and spinal cord. a TH staining shows TH ${ }^{+}$LC-NE neurons and fibers. b $\mathrm{TH}^{+}$neurons were counted manually, and data indicated that LC-NE neurons in WT mice are gradually lost with aging, although the neuron number of 24-month-old WT mice was not significantly less than that of 3-month-old and 12-month-old WT mice. In 12-month-old APP/PS1 mice, this number decreased significantly compared to that of the 12-month-old WT mice. Three brain slices from each mouse were analyzed and averaged. $n=6 . \mathrm{ns}$, not significant. ${ }^{*} P<0.01$. $\# P<0.01$ compared with 12-month-old APP/PS1 mice. 4V, fourth ventricle. $\mathbf{c} N E$ level in the brain and spinal cord of APP/PS1 and WT mice was detected with ELISA. No difference was detected in brain or spinal cord between groups. $n=$ 6, ns, not significant

fibers, $\mathrm{NET}^{+}$fibers were less in 12-month-old APP/PS1 mice than that in 24-month-old WT mice in DG and CA3 $(P=0.0002$ and $P=0.006$, respectively).

In the lumbar spinal cord of APP/PS1 and WT mice, $\mathrm{NET}^{+}$fibers decreased with aging in both APP/PS1 and WT mice $(P<0.0001$, Fig. 9). While the number of $\mathrm{NET}^{+}$fibers were similar between 3-month-old WT and APP/PS1 mice $(P=0.46)$, in 12-month-old APP/PS1 mice, less $\mathrm{NET}^{+}$fibers were detected compared with that of 12 -month-old WT mice $(9.33 \% \pm 0.49 \%$ vs $3.98 \% \pm$ $0.36 \%, P<0.0001)$. However, there was no difference in NET expression levels between 12-month-old AD and 24-month-old WT mice $(P>0.999)$. Overall, this suggests that many of the reduced $\mathrm{TH}^{+}$fibers were $\mathrm{NET}^{+}$fibers, corroborating our observation that LC-NE degeneration is prominent in APP/PS1 mice throughout the CNS.

\section{Discussion}

In the present study, we compared microglial activation, cytokine expression, and LC-NE neuronal degeneration in the brain and spinal cord of WT mice of 3-, 12-, and 24-months of age and APP/PS1 mice of 3- and 12months of age, representing times before and after clear $\mathrm{AD}$ neuropathogenesis $[43,44]$. We demonstrated that aging has a noticeable impact on both microglial activation and LC-NE degradation in WT mice. Importantly, APP/PS1 mice showed greater microglial activation and LC-NE neuronal degeneration than age-matched WT mice, which parallel with AD pathogenesis. Interestingly, microglial activation and LC-NE fiber loss in 12-month old APP/PS1 mice were even greater than in 24-monthold WT mice, suggesting that AD-like pathogenesis may have greater effects on these processes than aging. Despite these changes in LC-NE neuron number and fibers, 


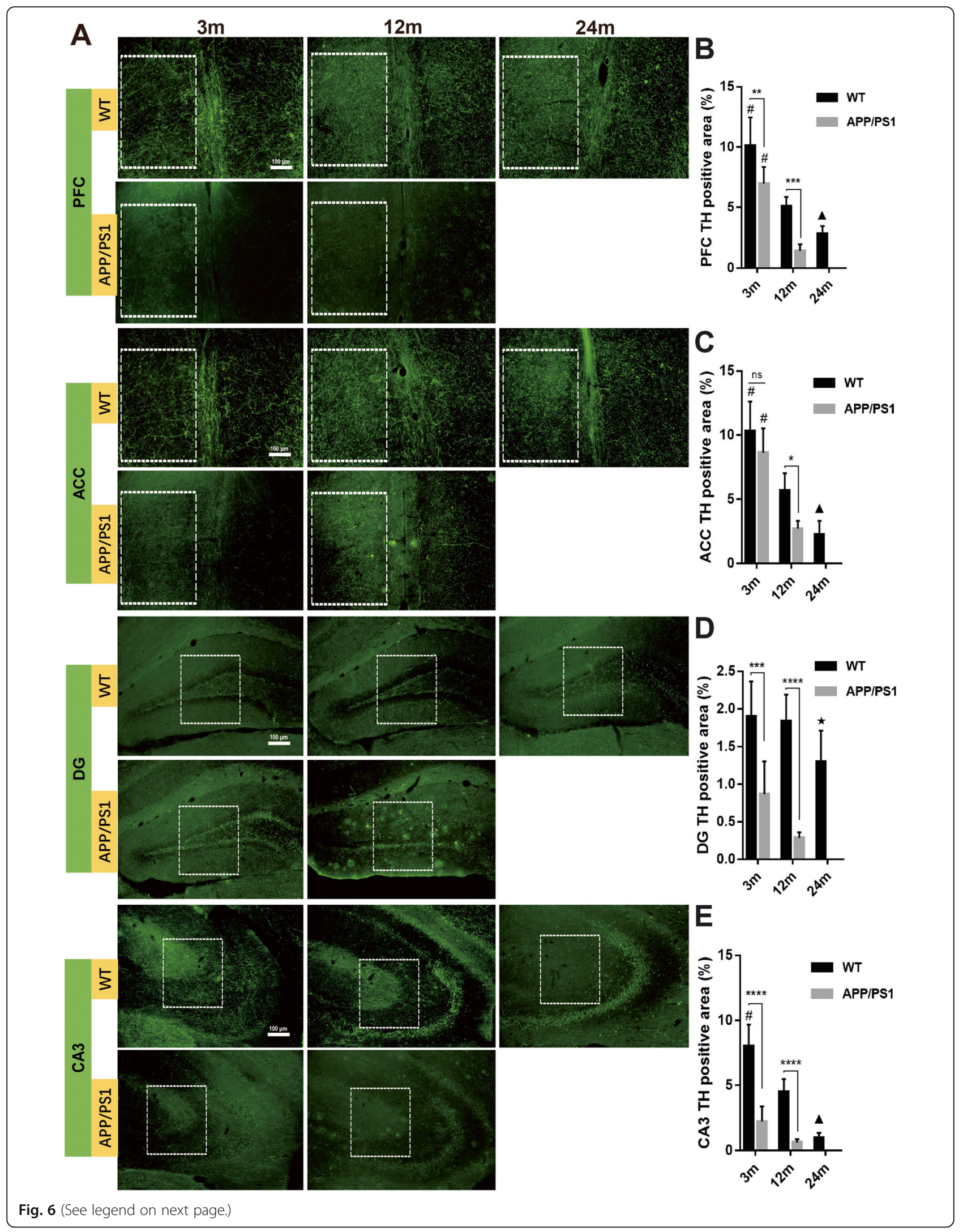


(See figure on previous page.)

Fig. 6 Detection of $\mathrm{TH}^{+}$nerve fibers in the brains of APP/PS1 and WT mice. a Immunofluorescence detection of $\mathrm{TH}^{+}$nerve fibers in different brain regions showed that in the $\mathbf{b}$ medial prefrontal cortex, $\mathbf{c}$ anterior cingulate, $\mathbf{d} \mathrm{DG}$, and $\mathbf{e} \mathrm{CA} 3, \mathrm{TH}^{+}$nerve fibers gradually decreased with aging. In 12-month-old APP/PS1 mice, $\mathrm{TH}^{+}$area was significantly reduced compared with WT mice of the same age and 3-month-old APP/PS1 mice. $\mathrm{TH}^{+}$area in the brain slices of 3-month-old and 12-month-old APP/PS1 mice was significantly lower than that of WT mice of the same age. In DG, $\mathrm{TH}^{+}$area of 12-month-old APP/PS1 mice was even significantly lower than that of 24-month-old WT mice. White box indicated region of interests used for the calculation of $\mathrm{TH}^{+}$area. $n=6$. ns, not significant. ${ }^{*} P<0.05$, ${ }^{*} P<0.01,{ }^{* * *} P<0.001,{ }^{* * *} P<0.0001$, $\# P<0.05$ compared with other time points in the same group. $\boldsymbol{\Delta} P<0.05$ compared with $12 \mathrm{~m}$ WT mice. $\star P<0.01$ compared with $12 \mathrm{~m}$ APP/PS1 mice

levels of NE in brain tissue remained constant. Finally, we observed increased cytokine expression in the brain and spinal cord of APP/PS1 mice but in distinctly different patterns in these two areas, suggesting potential functional differences in the activity of microglia in these areas.

In this study, microglial activation and cytokine expression were evaluated to reflect the neuroinflammatory status of the CNS in APP/PS1 and WT mice. Microglial activation increased with aging in both APP/ PS1 and WT mice; however, the severity and activation patterns were different based on genotype. Activated microglia in aged WT mice were evenly distributed in the brain and spinal cord, and number of activated microglia increased gradually with aging. However in APP/PS1 mice, activated microglia were found aggregated, particularly aggregated within and around $\mathrm{A} \beta 42^{+}$ plaques in the brain and spinal cord at 12 months of age. Studies both in vitro [45] and in vivo [13, 46] indicate that $A \beta$ peptides can promote microglial activation and aggregation. It has been reported that microglia are activated at an early stage of neuropathogenesis before senile plaques appear (50 days of age). Moreover, the activation of microglia remain constant in the later stages of plaque evolution (> 150 days of age) in APP/ PS1 mice [47], as perhaps microglial activation is triggered by oligomeric or soluble $A \beta$ at this early stage.

Additionally, we found that expression of several cytokines was increased in the APP/PS1 mouse brain and spinal cord. Particularly, from the 40 detected cytokines, the expression of 5 cytokines (C5a, CXCL9, CD54, IL16 , and IL-1 $\alpha$ ) in the brain and 5 cytokines (TIMP-1, TNF- $\alpha$, IL-23, CXCL12, and IL-27) in the spinal cord were upregulated in APP/PS1 mice. All of these upregulated cytokines have been reported to be released by microglia, or related to microglial inflammation; for example, IL- $1 \alpha$ and TNF- $\alpha$ are classically cytokine from DAM $[48,49]$. Previous studies have indicated dual roles of activated microglia, one by increasing phagocytosis of $A \beta$, therefore decreasing $A \beta$ plaque formation, and the other by secretion of cytokines and chemokines that can cause damage of the surrounding tissues, closer to the DAM pattern of activation seen with pathological changes [6,50]. Our data indicated more activated microglia and upregulated cytokines in APP/PS1 mice, suggesting that more severe neuroinflammation occurred during AD pathogenesis. Heneka et al. found that $\mathrm{NE}$ stimulation of microglia suppressed $A \beta$-induced

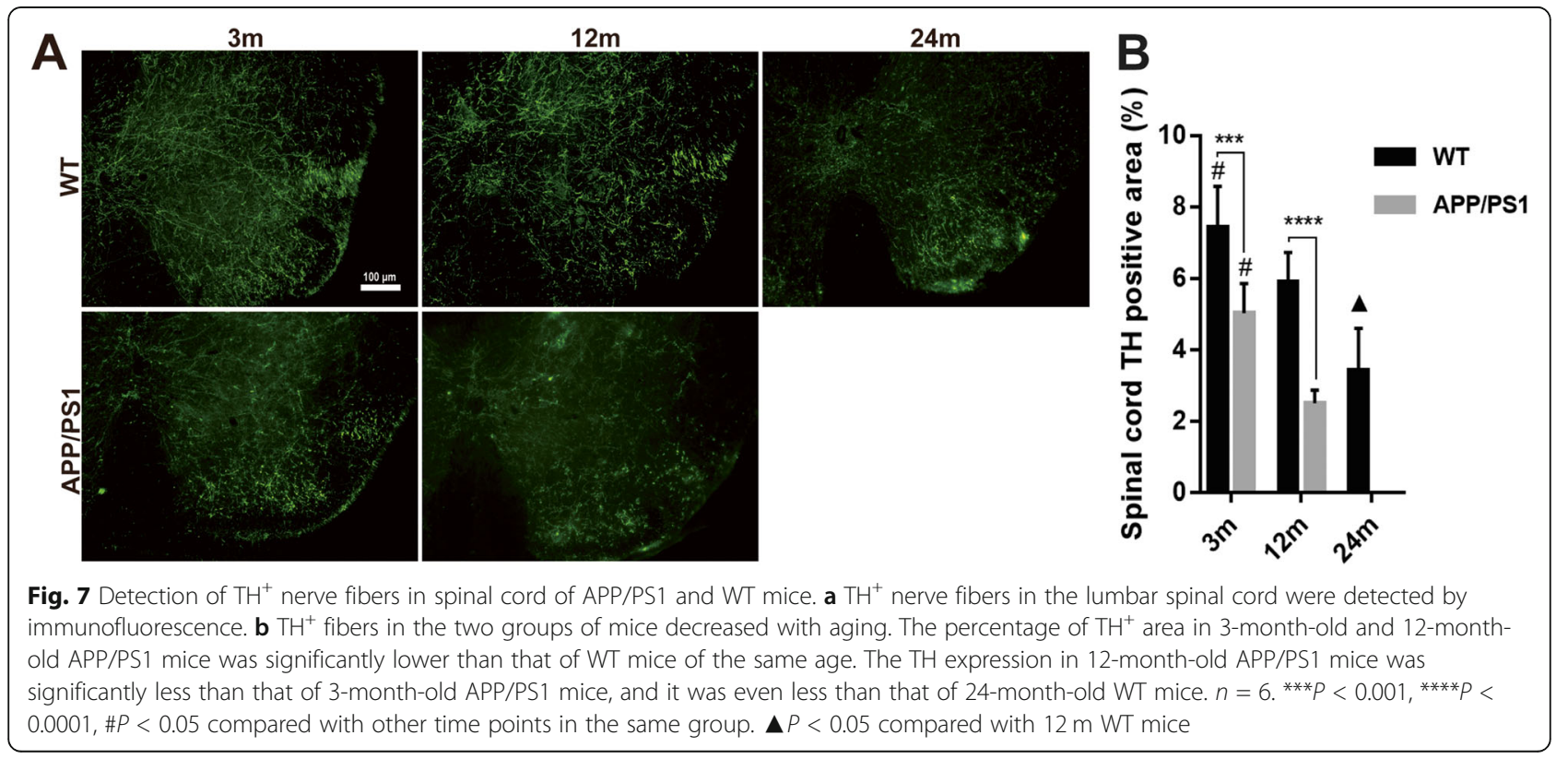




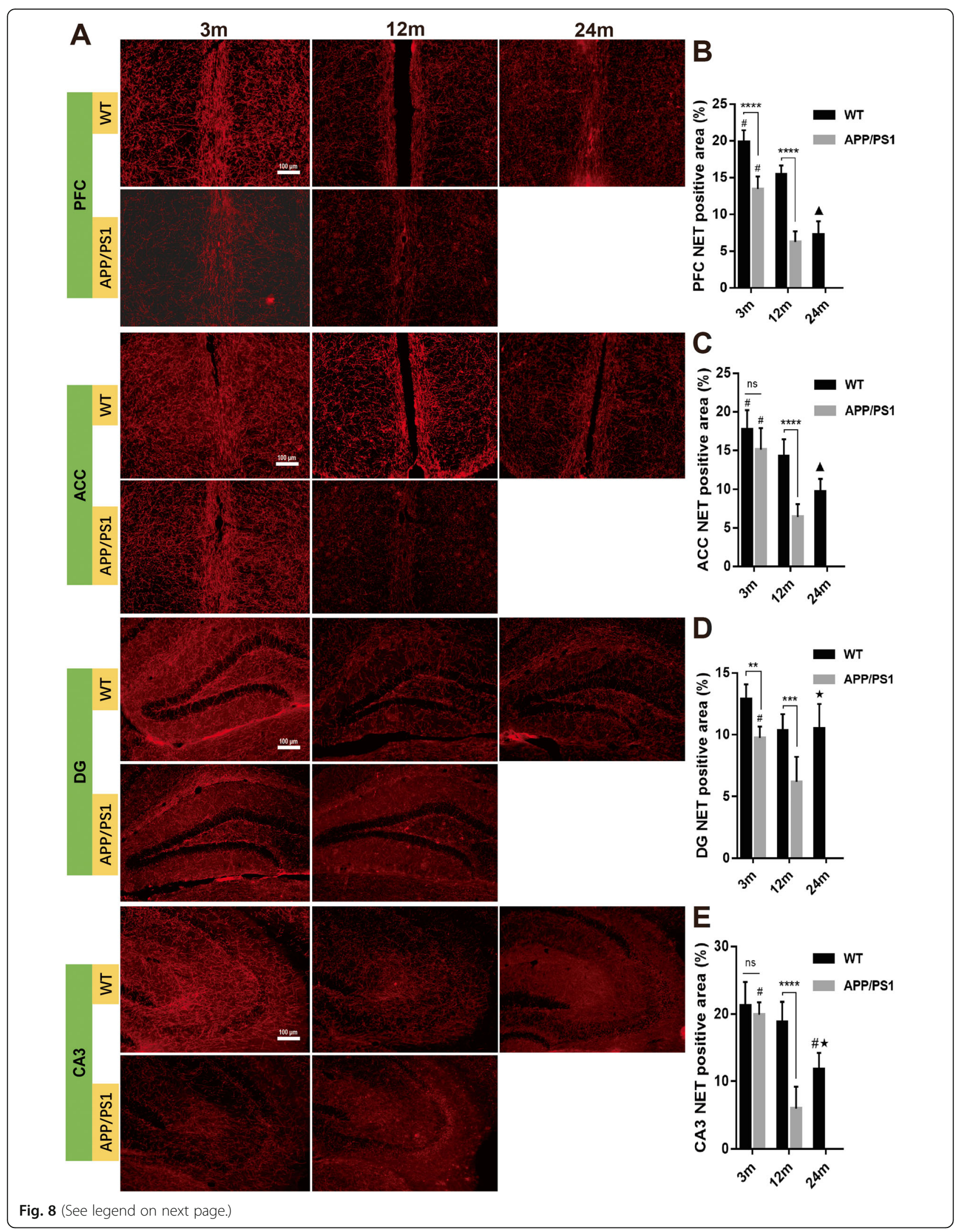


(See figure on previous page.)

Fig. 8 Detection of NET ${ }^{+}$nerve fibers in APP/PS1 and WT mice. a Immunofluorescence detected $\mathrm{NET}^{+}$nerve fibers in $\mathbf{b}$ medial prefrontal cortex, c anterior cingulate cortex, $\mathrm{d}$ DG, and e CA3. In these areas, $\mathrm{NET}^{+}$nerve fibers gradually decreased with aging. NET ${ }^{+}$nerve fibers in 12-month-old APP/PS1 mice were significantly less compared with WT mice of the same age and 3-month-old APP/PS1 mice. In ACC, DG, and CA3 of 12month-old APP/PS1 mice, the NET ${ }^{+}$area was less than that of 24-month-old WT mice. $n=6$. Comparisons between APP/PS1 mice and WT mice and comparisons among 3 WT groups were estimated with two-way ANOVA and followed by Tukey's post hoc multiple comparison tests. ns, not significant. ${ }^{*} P<0.01,{ }^{* *} P<0.001,{ }^{* * *} P<0.0001, \# P<0.05$ compared with other time points in the same group. $\mathbf{\Delta} P<0.05$ compared with $12-$ month-old WT mice. $\star P<0.01$ compared with 12-month-old APP/PS1 mice

cytokine and chemokine production and increased microglial migration and phagocytosis of $A \beta$ [23]. In APP-transgenic mice, degeneration of the LC increased expression of inflammatory mediators and resulted in elevated $A \beta$ deposition, reduced recruitment of microglia to $A \beta$ plaque sites, and impaired microglial $A \beta$ phagocytosis [23]. Of note, in this assay, we only detected cytokines in bulk brain tissues and were not able to separate the cortex and hippocampus, which limited our investigation in terms of the region-specific changes. Additionally, the number of differentially expressed cytokines by the cytokine protein array was relatively small, which reflected the limitation of this screening kit. In the future, more specific analyses of brain subregions with other methods such as mass-spectroscopy are needed to compare the expression differences of inflammation-related factors in AD models.

In this study, aging in WT mice did not lead to reduction in LC-NE neuron number, even between 3-monthold and 24-month-old mice. However, we found that the loss of LC-NE neurons in APP/PS1 mice was much more evident, corroborated by Mehla et al. [51] in $\mathrm{APP}^{\mathrm{NL}-\mathrm{G}-\mathrm{F} / \mathrm{NL}-\mathrm{G}-\mathrm{F}}$ mice, a knock-in model of pathogenic APP. In 16-23-month-old female APP/PS1 mice, LC neuron number was reduced by $24 \%$ compared with non-transgenic controls [52]. Another group found that in 16-17-month-old APP/PS1 mice, LC neurons were reduced by $23 \%$, although LC volume did not shrink [53]. In another study, $\mathrm{LC} \mathrm{TH}^{+}$neuron number was analyzed stereologically, and no difference was found between 12-month-old APP/PS1 and WT mice, although a significant decrease appeared in 18-month-old mice [54]. In another study, LC neuron volume was decreased in APP/PS1 mice at 12 months, and 18-month-old APP/ PS1 mice showed decreased $\mathrm{TH}^{+}$neuron volume in LC compared with 12-month-old APP/PS1 mice [54]. We detected more LC neuron loss in 12-month-old APP/ PS1 mice compared with 12-month-old WT mice, and the reason for the inconsistent results among these studies may be related to the different calculation methods for the number of LC neurons and differences in experimental design.

Perhaps surprisingly, there was no significant difference in NE levels in the brain and spinal cord between 12-month-old APP/PS1 mice and WT mice despite clear reduction in LC-NE neurons with the AD-like genotype. In order to determine whether increased axonal sprouting of LC-NE neurons accounted for the stable levels of

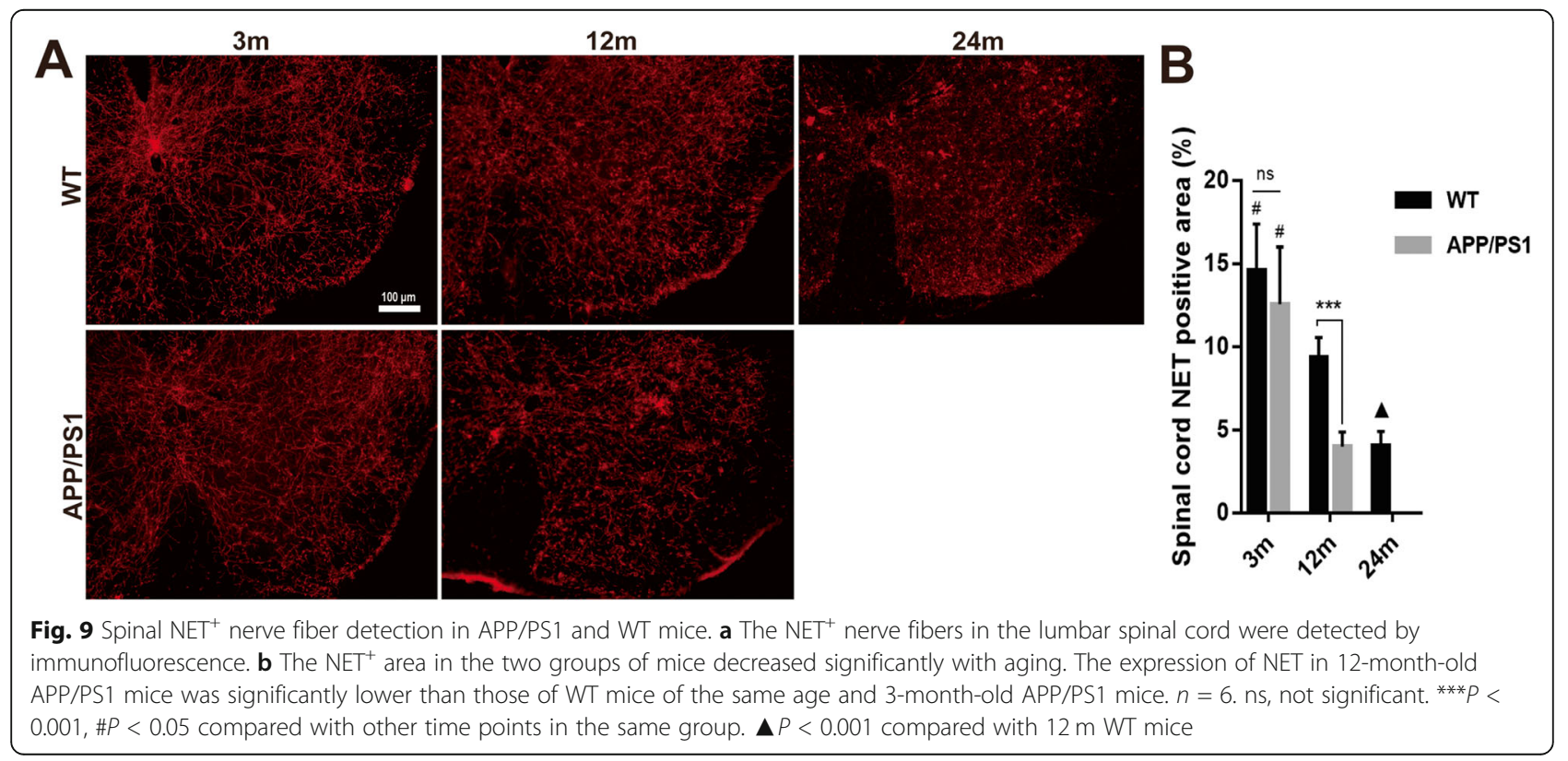


$\mathrm{NE}$ in the setting of profound LC-NE neuron loss, we measured the number of $\mathrm{TH}^{+}$and $\mathrm{NET}^{+}$nerve fibers. $\mathrm{TH}^{+}$nerve fibers represent axons of noradrenergic or dopaminergic neurons, while NET is restricted to noradrenergic neurons and is not present on neurons that release dopamine $[55,56]$. Our results demonstrated that compared with WT, the number of $\mathrm{TH}^{+}$nerve fibers was significantly reduced in the CNS of APP/PS1 mice, including PFC, ACC, DG, CA3, and lumbar spinal cord (Figs. 6 and 7). In addition, $\mathrm{NET}^{+}$nerve fibers also decreased significantly in these areas (Figs. 8 and 9). These results suggest that in APP/PS1 mice, the projection of LC-NE neurons to these brain regions is significantly decreased and NET expression is downregulated. Though it may seem contradictory that NE levels remain stable in the setting of decreased LC-NE cell bodies and nerve terminals, the reduction of NET may compensate for LC neuron degeneration. More intriguingly, this stabilization in NE levels may be part of compensatory electrophysiological changes resulting in increased excitability of LC-NE neurons, leading to greater NE release. This hyperexcitability is especially noticeable in pyramidal cells in early AD and is posited to lead to greater neurodegeneration in later $\mathrm{AD}$ through excitotoxic means [57]. The 12-month time point in APP/PS1 mice may represent a period where these compensatory changes are sufficient to maintain suitable NE levels while also exacerbating other pathological mechanisms that are spurring morphological degeneration. The large reduction of LC-NE nerve fibers will probably affect the amount of local NE transmitter release in its projective and distribution areas, i.e., in the synaptic and close extra-synaptic regions. As increasing evidence indicates that NE has important regulatory effects on the normal functions of microglia [24, 29], including inhibiting the activation of pro-inflammatory microglia [27, 30], it may be that these proposed more subtle changes in synaptic NE release spurs microglial activation. In support, supplying mice with the NE precursor L-threo-DOPS reduced microglial inflammation and restored microglial functions in NE-depleted mice [23]. However, this speculative decrease in synaptic NE needs to be confirmed with more sophisticated methods, though the clear reduction in LC-NE nerve terminals supports the hypothesis that regulation of microglia by LC-NE neurons is likely to be affected.

A large number of $A \beta$ plaques and activated microglia were observed in the DG and CA3 of the hippocampus, along with concomitant reduction in $\mathrm{TH}^{+}$fiber and $\mathrm{NET}^{+}$in these areas. While this suggests reduced LC-NE innervation of the hippocampus, this may also indicate reduced dopamine release from catecholaminergic nerve terminals from the $\mathrm{LC}$ or other brain regions, as $\mathrm{TH}$ staining is shared by dopaminergic and noradrenergic fibers. To characterize $\mathrm{TH}^{+}$fiber network in rat hippocampus, Ermine et al. used immunohistochemical and retrograde tracing techniques and found that $\mathrm{TH}$ and dopamine beta-hydroxylase $(\mathrm{D} \beta \mathrm{H})$ match well in rat brain. Especially in the rat hippocampus, all $\mathrm{TH}^{+}$fibers were $\mathrm{D} \beta \mathrm{H}^{+}$[58]. It should be noted that although the LC has always been regarded as a noradrenergic nucleus, increasing evidence suggests that LC releases dopamine to hippocampus $[58,59]$ and other brain areas [60]. Dopamine also activates downstream GPCRs similar to $\mathrm{NE}$ and likely affects neuroinflammation and the progression of $\mathrm{AD}[61,62]$. Dopamine can also inhibit microglial activation $[31,63]$, similarly to NE. Therefore, the decrease in LC-NE nerve fiber projection may result in decreased dopamine release from the LC, which may further affect the activity of microglia and neuroinflammation in various brain regions innervated by the LC.

To the best of our knowledge, this is the first report of comparisons of microglial activation and noradrenergic/ dopaminergic fibers in the spinal cord of APP/PS1 and WT mice. As part of the CNS, the spinal cord shows the same pathological changes as the $\mathrm{AD}$ brain, i.e., formation of $\mathrm{A} \beta^{+}$plaques $[17,64,65]$ and activated microglia around the plaques $[17,64]$. In the present study, compared with WT mice, increased microglial activation, upregulated cytokine expression, and decreased noradrenergic and dopaminergic neuron projections were also evident in the spinal cords of APP/PS1 mice. These data may warrant a hypothesis whereby aggravated neuroinflammation and possible neuronal damage in the spinal cord exists in $\mathrm{AD}$ patients, which may change central pain processing networks in the CNS. We found that $A \beta$ plaques in the lumbar spinal cord of 12-month-old APP/PS1 mice mainly appeared in the gray matter of the spinal cord, which is consistent with the phenomenon reported in the 5xFAD mice [64]. The spinal cord is involved in motor regulation and pain modulation, and these functions may be affected by increased spinal neuroinflammation in $\mathrm{AD}$ patients, as microglial activation and neuroinflammation in the spinal cord play a key role in central sensitization and maintenance of pathological pain [66].

In this study, we were unable to include APP/PS1 at 24 months of age due to the mortality issues, as it was extremely difficult to foster these mice until this age. Our hope is to continue this analysis in the future with AD mice with better survival, perhaps using the $\mathrm{APP}^{\mathrm{NLGF}}$ knock-in line.

\section{Conclusion}

Collectively, the evidence suggests that the elevated neuroinflammation in the brain and spinal cord of APP/PS1 mice is accompanied by the loss of LC-NE neuron somas and axon terminals. It is possible that this loss of 
LC-NE regulation further spurs pathological microglial activation, which may exacerbate central pain processing in $\mathrm{AD}$ patients with chronic pain.

\section{Abbreviations}

AD: Alzheimer's disease; ACC: Anterior cingulate cortex; BPSD: Behavioral and psychological symptoms of dementia; ELISA: Enzyme-linked immunosorbent assay; DAM: Disease-associated microglia; LPS: Lipopolysaccharide; LC: Locus coeruleus; NE: Norepinephrine; NET: Norepinephrine transporter; PFC: Prefrontal cortex; TH: Tyrosine hydroxylase; WT: Wild type

\section{Acknowledgements}

None.

\section{Authors' contributions}

This work was primarily conceived by $\mathrm{HD}$ and SC; data was collected by SC and GR and analyzed by SC and HD. Manuscript was written by SC, DWF, TY, and HD. Figures were produced by SC. All authors read and approved the final manuscript.

\section{Funding}

This work is supported by NIH grants RF1AG057884-03(Dong H) and partly supported by the National Natural Science Foundation of China (81660201 and 81960263 to (ao S) and the Excellent Young Talents Project of Zunyi Medical University (18zy-004 to Cao S).

\section{Availability of data and materials}

Please contact the author for data requests.

\section{Ethics approval and consent to participate}

All experiments were performed under protocols approved by the Northwestern University Animal Care and Use Committee, according to the current Guide for the Care and Use of Laboratory Animals (2011, eighth edition) and $\mathrm{NIH}$ guidelines for the treatment of animal subjects.

\section{Consent for publication}

Not applicable.

\section{Competing interests}

The authors declare that they have no competing interests.

\section{Author details}

'Department of Pain Medicine, Affiliated Hospital of Zunyi Medical University, 149 Dalian Street, Zunyi 563000, Guizhou, China. ${ }^{2}$ Guizhou Key Lab of Anesthesia and Organ Protection, Affiliated Hospital of Zunyi Medical University, 6 West Xuefu Street, Zunyi 563002, Guizhou, China. ${ }^{3}$ Department of Psychiatry and Behavioral Sciences, Northwestern University Feinberg School of Medicine, 303 East Chicago Avenue, Chicago, IL 60611, USA. ${ }^{4}$ Department of Psychiatry and Behavioral Sciences, University of Washington Medical Center, 1959 NE Pacific St, Seattle, WA 98195, USA.

Received: 30 June 2020 Accepted: 9 December 2020

Published online: 06 January 2021

\section{References}

1. Chakraborty S, Lennon JC, Malkaram SA, Zeng Y, Fisher DW, Dong H. Serotonergic system, cognition, and BPSD in Alzheimer's disease. Neurosci Lett. 2019;704:36-44.

2. Cao S, Fisher DW, Yu T, Dong H. The link between chronic pain and Alzheimer's disease. J Neuroinflammation. 2019;16:204.

3. Vossel KA, Tartaglia MC, Nygaard HB, Zeman AZ, Miller BL. Epileptic activity in Alzheimer's disease: causes and clinical relevance. Lancet Neurol. 2017;16: $311-22$.

4. Stubbs B, Thompson T, Solmi M, Vancampfort D, Sergi G, Luchini C, Veronese N. Is pain sensitivity altered in people with Alzheimer's disease? A systematic review and meta-analysis of experimental pain research. Exp Gerontol. 2016;82:30-8.

5. Jensen-Dahm C, Werner MU, Dahl JB, Jensen TS, Ballegaard M, Hejl AM, Waldemar G. Quantitative sensory testing and pain tolerance in patients with mild to moderate Alzheimer disease compared to healthy control subjects. Pain. 2014;155:1439-45.
6. Ofengeim D, Mazzitelli S, Ito Y, DeWitt JP, Mifflin L, Zou C, Das S, Adiconis X, Chen $\mathrm{H}$, Zhu H, et al. RIPK1 mediates a disease-associated microglial response in Alzheimer's disease. Proc Natl Acad Sci U S A. 2017;114:E8788e8797.

7. Marschallinger J, Iram T, Zardeneta M, Lee SE, Lehallier B. Lipid-dropletaccumulating microglia represent a dysfunctional and proinflammatory state in the aging brain. Nat Neurosci. 2020;23:194-208.

8. Mosher Kl, Wyss-Coray T. Microglial dysfunction in brain aging and Alzheimer's disease. Biochem Pharmacol. 2014;88:594-604.

9. Wegiel J, Wang KC, Imaki H, Rubenstein R, Wronska A, Osuchowski M, Lipinski WJ, Walker LC, LeVine H. The role of microglial cells and astrocytes in fibrillar plaque evolution in transgenic APP(SW) mice. Neurobiol Aging. 2001;22:49-61.

10. Venegas $C$, Kumar $S$, Franklin BS, Dierkes T, Brinkschulte R, Tejera D, Vieira-Saecker A, Schwartz S, Santarelli F, Kummer MP, et al. Microglia-derived ASC specks crossseed amyloid-beta in Alzheimer's disease. Nature. 2017;552:355-61.

11. Hopp SC, Lin Y, Oakley D, Roe AD, DeVos SL, Hanlon D, Hyman BT. The role of microglia in processing and spreading of bioactive tau seeds in Alzheimer's disease. J Neuroinflammation. 2018:15:269.

12. Maphis N, Xu G, Kokiko-Cochran ON, Jiang S, Cardona A, Ransohoff RM, Lamb BT, Bhaskar K. Reactive microglia drive tau pathology and contribute to the spreading of pathological tau in the brain. Brain. 2015;138:1738-55.

13. Ising C, Venegas C, Zhang S, Scheiblich H, Schmidt SV, Vieira-Saecker A, Schwartz S, Albasset S, McManus RM, Tejera D, et al. NLRP3 inflammasome activation drives tau pathology. Nature. 2019;575:669-73.

14. Hong S, Beja-Glasser VF, Nfonoyim BM, Frouin A, Li S, Ramakrishnan S, Merry KM, Shi Q, Rosenthal A, Barres BA, et al. Complement and microglia mediate early synapse loss in Alzheimer mouse models. Science. 2016;352:712-6.

15. Serrano-Pozo A, Betensky RA, Frosch MP, Hyman BT. Plaque-associated local toxicity increases over the clinical course of Alzheimer disease. Am J Pathol. 2016;186:375-84.

16. Solberg NO, Chamberlin R, Vigil JR, Deck LM, Heidrich JE, Brown DC, Brady Cl, Vander Jagt TA, Garwood M, Bisoffi M, et al. Optical and SPION-enhanced MR imaging shows that trans-stilbene inhibitors of NF-KB concomitantly lower Alzheimer's disease plaque formation and microglial activation in AßPP/PS-1 transgenic mouse brain. J Alzheimers Dis. 2014;40:191-212.

17. Aman Y, Pitcher T, Simeoli R, Ballard C, Malcangio M. Reduced thermal sensitivity and increased opioidergic tone in the TASTPM mouse model of Alzheimer's disease. Pain. 2016;157:2285-96.

18. Simic G, Babic Leko M, Wray S, Harrington CR, Delalle I, Jovanov-Milosevic N, Bazadona D, Buee L, de Silva R, Di Giovanni G, et al. Monoaminergic neuropathology in Alzheimer's disease. Prog Neurobiol. 2017;151:101-38.

19. Theofilas P, Ehrenberg AJ, Dunlop S, Di Lorenzo Alho AT, Nguy A, Leite REP, Rodriguez RD, Mejia MB, Suemoto CK, Ferretti-Rebustini REL, et al. Locus coeruleus volume and cell population changes during Alzheimer's disease progression: a stereological study in human postmortem brains with potential implication for early-stage biomarker discovery. Alzheimers Dement. 2017;13:236-46

20. Berridge CW, Waterhouse BD. The locus coeruleus-noradrenergic system: modulation of behavioral state and state-dependent cognitive processes. Brain Res Brain Res Rev. 2003:42:33-84.

21. Du WJ, Zhang RW, Li J, Zhang BB, Peng XL, Cao S, Yuan J, Yuan CD, Yu T, $\mathrm{Du} \mathrm{JL}$. The locus coeruleus modulates intravenous general anesthesia of zebrafish via a cooperative mechanism. Cell Rep. 2018;24:3146-3155.e3143.

22. Taylor BK, Westlund KN. The noradrenergic locus coeruleus as a chronic pain generator. J Neurosci Res. 2017;95:1336-46.

23. Heneka MT, Nadrigny F, Regen T, Martinez-Hernandez A, DumitrescuOzimek L, Terwel D, Jardanhazi-Kurutz D, Walter J, Kirchhoff F, Hanisch UK, Kummer MP. Locus ceruleus controls Alzheimer's disease pathology by modulating microglial functions through norepinephrine. Proc Natl Acad Sci U S A. 2010;107:6058-63.

24. Stowell RD, Sipe GO, Dawes RP, Batchelor HN, Lordy KA, Whitelaw BS, Stoessel MB, Bidlack JM, Brown E, Sur M. Noradrenergic signaling in the wakeful state inhibits microglial surveillance and synaptic plasticity in the mouse visual cortex. Nat Neurosci. 2019;22:1782-92.

25. Matthews KL, Chen CP, Esiri MM, Keene J, Minger SL, Francis PT. Noradrenergic changes, aggressive behavior, and cognition in patients with dementia. Biol Psychiatry. 2002:51:407-16.

26. German DC, Manaye KF, White CL 3rd, Woodward DJ, McIntire DD, Smith WK, Kalaria RN, Mann DM. Disease-specific patterns of locus coeruleus cell loss. Ann Neurol. 1992;32:667-76. 
27. Liu H, Leak RK, Hu X. Neurotransmitter receptors on microglia. Stroke Vasc Neurol. 2016;1:52-8.

28. Mori K, Ozaki E, Zhang B, Yang L, Yokoyama A, Takeda I, Maeda N, Sakanaka $M$, Tanaka J. Effects of norepinephrine on rat cultured microglial cells that express alpha1, alpha2, beta1 and beta2 adrenergic receptors. Neuropharmacology. 2002;43:1026-34.

29. Liu YU, Ying Y, Li Y, Eyo UB, Chen T, Zheng J, Umpierre AD, Zhu J, Bosco $\mathrm{DB}$, Dong $\mathrm{H}$. Neuronal network activity controls microglial process surveillance in awake mice via norepinephrine signaling. Nat Neurosci. 2019; 22:1771-81.

30. Markus T, Hansson SR, Cronberg T, Cilio C, Wieloch T. Ley D: betaAdrenoceptor activation depresses brain inflammation and is neuroprotective in lipopolysaccharide-induced sensitization to oxygenglucose deprivation in organotypic hippocampal slices. J Neuroinflammation. 2010;7:94.

31. Farber K, Pannasch U, Kettenmann H. Dopamine and noradrenaline control distinct functions in rodent microglial cells. Mol Cell Neurosci. 2005;29:12838.

32. Thery C, Dobbertin A, Mallat M. Downregulation of in vitro neurotoxicity of brain macrophages by prostaglandin E2 and a beta-adrenergic agonist. Glia. 1994;11:383-6.

33. Gannon M, Che P, Chen Y, Jiao K, Roberson ED, Wang Q. Noradrenergic dysfunction in Alzheimer's disease. Front Neurosci. 2015;9:220.

34. Elrod R, Peskind ER, DiGiacomo L, Brodkin KI, Veith RC, Raskind MA. Effects of Alzheimer's disease severity on cerebrospinal fluid norepinephrine concentration. Am J Psychiatry. 1997;154:25-30.

35. Gannon M, Wang Q. Complex noradrenergic dysfunction in Alzheimer's disease: low norepinephrine input is not always to blame. Brain Res. 1702; 2019:12-6.

36. Paxinos G, Franklin KB. Paxinos and Franklin's the mouse brain in stereotaxic coordinates: Academic press; 2019.

37. Watson C, Paxinos G, Kayalioglu G, Heise C. Atlas of the mouse spinal cord: The spinal cord. Elsevier; 2009. p. 308-79.

38. Cao S, Li J, Yuan J, Zhang D, Yu T. Fast localization and sectioning of mouse locus coeruleus. Biomed Res Int. 2020;2020:4860735.

39. Bravo L, Torres-Sanchez S, Alba-Delgado C, Mico JA, Berrocoso E. Pain exacerbates chronic mild stress-induced changes in noradrenergic transmission in rats. Eur Neuropsychopharmacol. 2014:24:996-1003.

40. DiBona VL, Zhu W, Shah MK, Rafalia A, Ben Cheikh H, Crockett DP. Loss of Par1b/MARK2 primes microglia during brain development and enhances their sensitivity to injury. J Neuroinflammation. 2019;16:11.

41. Fan Z, Brooks DJ, Okello A, Edison P. An early and late peak in microglial activation in Alzheimer's disease trajectory. Brain. 2017;140:792-803.

42. Szot P, White SS, Greenup JL, Leverenz JB, Peskind ER, Raskind MA. Changes in adrenoreceptors in the prefrontal cortex of subjects with dementia: evidence of compensatory changes. Neuroscience. 2007;146:471-80.

43. Zhou L, Liu J, Dong D, Wei C, Wang R. Dynamic alteration of neprilysin and endothelin-converting enzyme in age-dependent APPswe/PS1dE9 mouse model of Alzheimer's disease. Am J Transl Res. 2017:9:184-96.

44. Georgevsky D, Retsas S, Raoufi N, Shimoni O, Golzan SM. A longitudinal assessment of retinal function and structure in the APP/PS1 transgenic mouse model of Alzheimer's disease. Transl Neurodegener. 2019;8:30.

45. Xu H, Rajsombath MM, Weikop P, Selkoe DJ. Enriched environment enhances beta-adrenergic signaling to prevent microglia inflammation by amyloid-beta. EMBO Mol Med. 2018;10:e8931.

46. Gao Y, Liu EJ, Wang WJ, Wang YL, Li XG, Wang X, Li SH, Zhang SJ, Li MZ, Zhou QZ, et al. Microglia CREB-phosphorylation mediates amyloid-betainduced neuronal toxicity. J Alzheimers Dis. 2018;66:333-45.

47. Scheffler K, Stenzel J, Krohn M, Lange C, Hofrichter J, Schumacher T, Brüning T, Plath AS, Walker L, Pahnke J. Determination of spatial and temporal distribution of microglia by $230 \mathrm{~nm}$-high-resolution, high-throughput automated analysis reveals different amyloid plaque populations in an APP/ PS1 mouse model of Alzheimer's disease. Curr Alzheimer Res. 2011:8:781-8.

48. Babić Leko M, Nikolac Perković M, Klepac N, Štrac D, Borovečki F, Pivac N, Hof PR, Šimić G. IL-1ß, IL-6, IL-10, and TNFa single nucleotide polymorphisms in human influence the susceptibility to Alzheimer's disease pathology. J Alzheimers Dis. 2020;75:1029-47.

49. Aksenova M, Sybrandt J, Cui B, Sikirzhytski V, Ji H, Odhiambo D, Lucius MD, Turner JR, Broude E, Peña E, et al. Inhibition of the dead box RNA helicase 3 prevents HIV-1 Tat and cocaine-induced neurotoxicity by targeting microglia activation. J Neurolmmune Pharmacol. 2020;15:209-23.
50. Rogers J, Lue LF. Microglial chemotaxis, activation, and phagocytosis of amyloid beta-peptide as linked phenomena in Alzheimer's disease. Neurochem Int. 2001;39:333-40.

51. Mehla J, Lacoursiere SG, Lapointe V, McNaughton BL, Sutherland RJ, McDonald RJ, Mohajerani MH. Age-dependent behavioral and biochemical characterization of single APP knock-in mouse (APP(NL-G-F/NL-G-F)) model of Alzheimer's disease. Neurobiol Aging. 2019;75:25-37.

52. O'Neil JN, Mouton PR, Tizabi Y, Ottinger MA, Lei DL, Ingram DK, Manaye KF. Catecholaminergic neuronal loss in locus coeruleus of aged female dtg APP/PS1 mice. J Chem Neuroanat. 2007;34:102-7.

53. Liu L, Luo S, Zeng L, Wang W, Yuan L, Jian X. Degenerative alterations in noradrenergic neurons of the locus coeruleus in Alzheimer's disease. Neural Regen Res. 2013;8:2249-55.

54. Liu Y, Yoo MJ, Savonenko A, Stirling W, Price DL, Borchelt DR, Mamounas L, Lyons WE, Blue ME, Lee MK. Amyloid pathology is associated with progressive monoaminergic neurodegeneration in a transgenic mouse model of Alzheimer's disease. J Neurosci. 2008;28:13805-14.

55. Schroeter S, Apparsundaram S, Wiley RG, Miner LH, Sesack SR, Blakely RD. Immunolocalization of the cocaine- and antidepressant-sensitive Inorepinephrine transporter. J Comp Neurol. 2000;420:211-32.

56. Mandela P, Ordway GA. The norepinephrine transporter and its regulation. J Neurochem. 2006:97:310-33.

57. Šišková Z, Justus D, Kaneko H, Friedrichs D, Henneberg N, Beutel T, Pitsch J, Schoch S, Becker A, von der Kammer H, Remy S. Dendritic structural degeneration is functionally linked to cellular hyperexcitability in a mouse model of Alzheimer's disease. Neuron. 2014;84:1023-33.

58. Ermine CM, Wright JL, Parish CL, Stanic D, Thompson LH. Combined immunohistochemical and retrograde tracing reveals little evidence of innervation of the rat dentate gyrus by midbrain dopamine neurons. Front Biol. 2016;11:246-55

59. Kempadoo KA, Mosharov EV, Choi SJ, Sulzer D, Kandel ER. Dopamine release from the locus coeruleus to the dorsal hippocampus promotes spatial learning and memory. Proc Natl Acad Sci U S A. 2016:113:14835-40.

60. Beas BS, Wright BJ, Skirzewski M. The locus coeruleus drives disinhibition in the midline thalamus via a dopaminergic mechanism. Nat Neurosci. 2018; 21:963-73.

61. Nam E, Derrick JS, Lee S, Kang J, Han J, Lee SJC, Chung SW, Lim MH. Regulatory activities of dopamine and its derivatives toward metal-free and metal-induced amyloid-beta aggregation, oxidative stress, and inflammation in Alzheimer's disease. ACS Chem Neurosci. 2018;9:2655-66.

62. Nobili A, Latagliata EC, Viscomi MT, Cavallucci V, Cutuli D, Giacovazzo G, Krashia P. Dopamine neuronal loss contributes to memory and reward dysfunction in a model of Alzheimer's disease. Nat Commun. 2017;8:14727.

63. Dominguez-Meijide A, Rodriguez-Perez Al, Diaz-Ruiz C, Guerra MJ, Labandeira-Garcia JL. Dopamine modulates astroglial and microglial activity via glial renin-angiotensin system in cultures. Brain Behav Immun. 2017;62: 277-90

64. Chu TH, Cummins K, Sparling JS, Tsutsui S, Brideau C, Nilsson KPR, Joseph JT, Stys PK. Axonal and myelinic pathology in 5xFAD Alzheimer's mouse spinal cord. PLoS One. 2017;12:e0188218.

65. Li JM, Xue ZQ, Deng SH, Luo XG, Patrylo PR, Rose GW, Cai H, Cai Y, Yan XX. Amyloid plaque pathogenesis in 5XFAD mouse spinal cord: retrograde transneuronal modulation after peripheral nerve injury. Neurotox Res. 2013; 24:1-14.

66. Chen G, Zhang YQ, Qadri YJ, Serhan CN, Ji RR. Microglia in pain: detrimental and protective roles in pathogenesis and resolution of pain. Neuron. 2018; 100:1292-311.

\section{Publisher's Note}

Springer Nature remains neutral with regard to jurisdictional claims in published maps and institutional affiliations. 